\title{
AN INVESTIGATION ON PREDICTORS OF LIFE SATISFACTION AMONG THE ELDERLY
}

\author{
Sima Ataollahi Eshkoor ${ }^{1 *}$, Tengku Aizan Hamid ${ }^{2 *}$, Chan Yoke Mun ${ }^{3}$, \\ Suzana Shahar ${ }^{4}$ \\ ${ }^{1}$ Institute of Gerontology, Universiti Putra Malaysia, Selangor, Malaysia, simaataolahi@yahoo.com \\ ${ }^{2}$ Institute of Gerontology, Universiti Putra Malaysia, Selangor, Malaysia, aizan@upm.edu.my \\ ${ }^{3}$ Institute of Gerontology, Universiti Putra Malaysia, Selangor, Malaysia, cym@upm.edu.my \\ ${ }^{4}$ Faculty of Health Sciences, Universiti Kebangsaan Malaysia, Malaysia, suzanas@medic.ukm.my \\ ${ }^{*}$ Corresponding Authors
}

\begin{abstract}
In the elderly, the perception of life satisfaction and quality of life are related to many factors such as healthy life-span, chronic illnesses, expectations and self-perception of ageing. This study aimed to determine the effects of variables including age, employment, education, cognition, ethnicity, debt, sex differences, intimacy capability, sleep hours, taking salary, home ownership status, and living with a partner on life satisfaction in the Malaysian elderly. This project recruited 2322 subjects who were non-institutionalized Malaysian elderly aged 60 years and above. Life satisfaction was measured by asking in general 'Are you satisfied with your current life'. The multiple logistic regression analysis was used to predict the effects of susceptible variables on life satisfaction in subjects. Approximately, $90.4 \%$ of samples reported that they were satisfied with their current life. The results of multiple regression analysis showed that ethnic Malay (odds ratio $[O R]=1.50 ; p=$ $0.014)$, and living with a partner $(O R=1.51 ; p=0.015)$ were significantly associated with the higher level of life satisfaction in respondents $(p<0.05)$. Age, employment, cognition, debt, education, taking salary, intimacy capability, sex differences, sleep hours, and home ownership status did not show any significant effects on life satisfaction in subjects $(p>0.05)$. It was concluded that ethnic Malay and living with a partner prominently enhanced the level of life satisfaction in respondents.
\end{abstract}

Keywords: Elderly, Quality of life, Life Satisfaction.

\section{INTRODUCTION}

Life satisfaction is an individual's subjective well-being that represents a person's quality of life (QOL) (Anand and Arora, 2009; Kaufman et al., 2010). QOL is a concept that is evaluated based on own goals, concerns, cultures, expectations, standards, living places and value systems that a person has (Netuveli and Blane, 2008). QOL and life satisfaction are correlated to a healthy and productive life (Anand and Arora, 2009) and being satisfied in life reflects the condition of having a good life (Kaliterna et al., 2004). Life satisfaction is a subjective judgment (Anand and Arora, 2009) that is based on the comparison between the expectations and possessions of a person in whole life rather than that in a certain condition (Melek, 2004). It is referred to the 
feelings and happiness that can be associated with emotions, moods, cognitive status and the background of a person (Diener, 2009). Satisfaction with life shows the feeling of pleasure that a person has regarding own expectations and circumstances in life as a whole (Jan and Masood, 2007). The feeling of life satisfaction in the older people indicates the abilities in adjustment and adaption with situations they deal with (Hervé et al., 2012). Life satisfaction is often used as an indicator to measure successful aging (García et al., 2011), which is characterized by physical health, mental functioning, social active, and financially secure (Eshkoor et al., 2014). This concept is a central theme of gerontology and gerontologist attempt to assist older people to age well.

There are many factors including poor health, poverty, disability, loneliness and anxiety that can affect the feeling of life satisfaction in the elderly. For instant, limited income can sometimes have a great impact on life satisfaction in the elderly by influencing their ability to pay for treatments, medicines and other needs such as glasses (Borg et al., 2006). Aging is the other significant obstacle to gain satisfaction in life in the elderly because of causing worthless and powerless. However, aging is an unpreventable process with biological, chronological and social aspects (Melek, 2004) and also the number of older people is increasing; therefore, it is of utmost importance to improve life satisfaction in this specific age group. Accordingly, this study aimed to study various variables including age, education, ethnicity, salary, debt, employment, cognition, intimacy capability, sleep hours, sex differences, home ownership status, and living with a partner on life satisfaction in the non-institutionalized elderly in Malaysia.

\section{METHODOLOGY}

The project (Project Code: NN-060-2013) was a heterogeneous prospective survey entitled "Neuroprotective Model for Healthy Longevity among the Malaysian Elderly" and carried out in co-operation with Universiti Kebangsaan Malaysia (UKM), and Institute of Gerontology, Universiti Putra Malaysia (UPM). The approval and permission for conducting the study were received from the Ethical Committee of Universiti Kebangsaan Malaysia. This project recruited 2322 elderly who were Malaysian population aged 60 years and above, residing in non-institutional places. Samples were collected from different ethnicities in Malaysia involving Malays, Chinese, Indians and others that were classified as two groups: (0) Non-Malays and (1) Malays. The elderly who were living in institutions and bedridden, were excluded. Then, participants were gathered at community halls and centers for interview session and health screening. Trained fieldworkers conducted a face-to-face interview. The present study evaluated the effects of age, ethnicity, education, sex differences, debt, salary, employment, cognition, home ownership status, intimacy capability, sleep hours and living with a partner on life satisfaction in respondents. A questionnaire was used to collect data on socio-demography parameters and other variables. Life satisfaction was measured through asking in general 'Are you satisfied with your current life' on a 4-point Likert scale including very satisfactory, satisfactory, not satisfied and not very satisfactory. The respondents who reported not satisfactory and not very satisfactory were placed in a group of not being satisfied with life and those with the answers of satisfactory and very satisfactory were designated as the second group and marked as life satisfaction.

\section{1 Statistical analysis}

The prevalence of cognitive decline was computed for all subjects with regard to their independent variables. The bivariate analysis was carried out using a series of chi-square tests to determine the association between life satisfaction and each variable among samples. The multivariate logistic regression analysis was applied to predict the effects of independent variables on life satisfaction. Odds ratios (OR) with $95 \%$ confidence intervals $(95 \% \mathrm{Cl})$ were computed. The critical level for rejection of null hypothesis was considered to be a $p$ value of $5 \%$, two-tailed. All analyses were done using the Statistical Package for the IBM Social Sciences (SPSS) software version 22.0 (Chicago, IL, USA).

\section{RESULTS}

Analysis was run on data collected from 2322 subjects who were the Malaysian elderly. The prevalence of life satisfaction was $90.4 \%$ (95\% Cl 89.13-91.53) among subjects (Table 1).

Table 1: Prevalence of life satisfaction among 2322 elderly

\begin{tabular}{|c|c|c|c|}
\hline Character & $\mathrm{n}$ & $\mathrm{n}(\%)$ & $95 \% \mathrm{Cl}$ \\
\hline Life satisfaction & & & \\
\hline Yes & 2099 & 90.4 & $89.13-91.53$ \\
\hline No & 168 & 7.2 & $6.26-8.37$ \\
\hline
\end{tabular}


It was found that the percentage of life satisfaction was $92.7 \%$ among the subjects who had own home and $92.4 \%$ among the subjects who did not have own home. The prevalence of life satisfaction was $91.3 \%$ among the subjects with sleeping less than 6 hours and $92.8 \%$ among those with sleeping 6 hours or more. The findings indicated that the percentage of life satisfaction among the respondents who were employed $(93.7 \%)$ was approximately close to those who were not employed $(92.3 \%)$. In addition, the rate of life satisfaction was $91.6 \%$ among the respondents who had debt and $92.7 \%$ among those without debt. The results indicated that the percentage of life satisfaction among the subjects who were taking salary (92\%) was approximately close to those without taking salary (92.7\%).

The prevalence of life satisfaction among the subjects with normal cognition and cognitive decline was 93.9 and $92 \%$, respectively. The rate of life satisfaction was $93.6 \%$ among the subjects who were living with a partner and $90.7 \%$ among those without living with a partner. The percentage of life satisfaction among the subjects with and without intimacy capability was 91.8 and $92.8 \%$ respectively. Furthermore, the results showed that the prevalence of life satisfaction among males $(92.6 \%)$ was close to females $(92.6 \%)$. The results showed that $92.6 \%$ of the elderly who were less than 75 years and $92.4 \%$ of the elderly who were 75 years and above were satisfied in their life. Moreover, the prevalence of life satisfaction was $92.9 \%$ among educated subjects and $91.3 \%$ among non-educated subjects. Among all samples, $93.5 \%$ of Malays and $91.1 \%$ of non-Malays reported being satisfied with their life.

Bivariate analysis established the association of life satisfaction with each variable by chi-square tests. The results showed that ethnicity $(x 2=4.37, p=0.037)$, and living with a partner $(x 2=6.43, p=0.011)$ were significantly associated with the feeling of life satisfaction among respondents. In addition, it was fund that life satisfaction was irrelevant to age, employment, debt, cognition, intimacy capability, sex differences, sleep hours, home ownership status, and taking salary ( $p>0.05)$ (Table2).

Table 2: Prevalence of life satisfaction and associations with socio-demographic factors

\begin{tabular}{|c|c|c|c|c|c|c|}
\hline & Whole & $\mathrm{n}$ & $\mathrm{n} \%$ & $95 \% \mathrm{Cl}$ & $x^{2}$ & $p$ value \\
\hline \multicolumn{7}{|l|}{ Home Owner } \\
\hline No & 950 & 878 & 92.4 & $90.56-93.94$ & 0.06 & 0.811 \\
\hline Yes & 1313 & 1217 & 92.7 & $91.15-93.98$ & & \\
\hline \multicolumn{7}{|l|}{ Sleep hours } \\
\hline Less than 6 hours & 400 & 365 & 91.3 & $88.07-93.64$ & 1.19 & 0.276 \\
\hline 6 hours or more & 1786 & 1658 & 92.8 & $91.54-93.94$ & & \\
\hline \multicolumn{7}{|l|}{ Employment } \\
\hline No & 1742 & 1607 & 92.3 & $90.9-93.41$ & 1.25 & 0.263 \\
\hline Yes & 510 & 478 & 93.7 & $91.28-95.52$ & & \\
\hline \multicolumn{7}{|l|}{ Debt } \\
\hline No & 2111 & 1956 & 92.7 & $91.47-93.7$ & 0.23 & 0.632 \\
\hline Yes & 155 & 142 & 91.6 & $86.18-95.03$ & & \\
\hline \multicolumn{7}{|l|}{ Salary } \\
\hline No & 1943 & 1801 & 92.7 & $91.45-93.77$ & 0.21 & 0.649 \\
\hline Yes & 324 & 298 & 92 & $88.51-94.47$ & & \\
\hline \multicolumn{7}{|l|}{ Cognitive Decline } \\
\hline No & 705 & 662 & 93.9 & $91.88-95.44$ & 2.55 & 0.110 \\
\hline Yes & 1537 & 1414 & 92 & $90.54-93.25$ & & \\
\hline \multicolumn{7}{|l|}{ Living with partner } \\
\hline No & 795 & 721 & 90.7 & 88.47-92.52 & 6.43 & 0.011 \\
\hline Yes & 1472 & 1378 & 93.6 & $92.24-94.75$ & & \\
\hline \multicolumn{7}{|l|}{ Intimacy Capability } \\
\hline No & 1744 & 1619 & 92.8 & $91.52-93.95$ & 0.66 & 0.418 \\
\hline Yes & 510 & 468 & 91.8 & $89.05-93.85$ & & \\
\hline \multicolumn{7}{|l|}{ Sex Differences } \\
\hline Male & 1085 & 1005 & 92.6 & $90.92-94.04$ & 0.00 & 0.948 \\
\hline Female & 1182 & 1094 & 92.6 & $90.91-93.91$ & & \\
\hline \multicolumn{7}{|l|}{ Ethnicity } \\
\hline Malays & 1425 & 1332 & 93.5 & $92.07-94.64$ & 4.37 & 0.037 \\
\hline Non-Malays & 842 & 767 & 91.1 & 88.97-92.83 & & \\
\hline \multicolumn{7}{|l|}{ Age } \\
\hline Less than 75 & 1805 & 1672 & 92.6 & $91.33-93.75$ & 0.02 & 0.879 \\
\hline
\end{tabular}


IJASOS- International E-Journal of Advances in Social Sciences, Vol. I, Issue 2, August 2015

\begin{tabular}{|l|c|c|c|c|c|c|}
\hline 75 years and above & 462 & 427 & 92.4 & $89.6-94.5$ & & \\
\hline Educational level & & & & & & \\
\hline No & 472 & 431 & 91.3 & $88.42-93.53$ & 1.41 & 0.234 \\
\hline Yes & 1795 & 1668 & 92.9 & $91.64-94.02$ & & \\
\hline
\end{tabular}

Significant at the 0.05 level using the chi-square test

The findings of multiple logistic regression analysis showed that living with a partner $(p=0.015)$ and ethnic Malay $(p=0.014)$ were significantly associated with the feeling of life satisfaction in respondents $(p<$ $0.05)$. It was found that living with a partner $(\mathrm{OR}=1.51,95 \% \mathrm{Cl} 1.08-2.10)$ and ethnic Malay $(\mathrm{OR}=1.50$, $95 \% \mathrm{Cl} 1.09-2.08)$ significantly increased life satisfaction in subjects $(p<0.05)$. Cognition $(p=0.097)$, and education $(p=0.863)$ were not found significant predictors of life satisfaction in samples $(p>0.05)$ (Table 3$)$.

Table 3: Prevalence of life satisfaction and associations derived by logistic regression analysis

\begin{tabular}{|c|c|c|c|c|c|c|}
\hline & \multirow[b]{2}{*}{ B } & \multirow{2}{*}{ SE } & \multirow[b]{2}{*}{$p$ value } & \multirow{2}{*}{ OR } & \multicolumn{2}{|c|}{$95 \% \mathrm{Cl}$ for OR } \\
\hline & & & & & Lower & Upper \\
\hline Cognition & -0.313 & 0.189 & 0.097 & 0.73 & 0.51 & 1.06 \\
\hline Living with partner & 0.411 & 0.170 & 0.015 & 1.51 & 1.08 & 2.10 \\
\hline Ethnicity & 0.406 & 0.165 & 0.014 & 1.50 & 1.09 & 2.08 \\
\hline Education & 0.034 & 0.198 & 0.863 & 1.04 & 0.70 & 1.53 \\
\hline
\end{tabular}

Significant at the 0.05 level using the logistic regression analysis

Hosmer-Lemeshow test: $X^{2}(8)=8.82 ; p=0.184$

\section{DISCUSSION}

Different factors such as cognition, independency, emotional status, physical activity, social support and socio-demographic parameters can affect life satisfaction (Onishi et al., 2010). As the number of elderly people is on the rise; therefore, further studies are needed to improve life satisfaction in this group. Thus, this study was designed to identify the effects of age, ethnicity, education, salary, cognition, employment, debt, sex differences, intimacy capability, sleep hours, home ownership status, and living with a partner on life satisfaction among the non-institutionalized elderly in Malaysia. It was found that ethnic Malay and living with a partner were statistically significant predictors of life satisfaction in subjects.

Our result confirmed previous reports indicating the prominent effect of partnership on the increased life satisfaction. One explanation for the effect can be the positive impact of close relationship on covering basic and universal human needs (Diener et al., 2000). Furthermore, interpersonal intimacy and emotional support can enhance well-being and life satisfaction (Diener et al., 2000; Troxel et al., 2007). It has been noted that a good interpersonal network between partners along with a good personal concept about aging process (Silva 2014) positively affect life satisfaction in the elderly (DeLamater and Moorman, 2007). Life satisfaction was also prominently observed in the Malay elderly compared to the non-Malays. Such difference can be due to the different effects of religious beliefs, lifestyle and cultures (Jean-Louis et al., 2001). Social and cultural parameters can impact one's perception regarding life satisfaction (Hombrados-Mendieta et al., 2013).

The findings showed that age, employment, debt, cognition, sleep hours, sex differences, taking salary, intimacy capability, and home ownership status were unrelated to life satisfaction in subjects. It seems that these factors affect the feeling of life satisfaction via moderating effects. These results established that such factors may sometimes affect subjective well-being but there is no guarantee (Diener 1994). As aging is inevitable and the world's population is aging rapidly, main focus is now to elevate primary care, promote life satisfaction and increase successfully aging.

\section{LIMITATIONS}

There are some limitations to this study. First, self-reported data can limit to determine correctly the level of life satisfaction among subjects. Thus, more research with developed tools and more variables are needed to assess the effects of age-related problems on life satisfaction with a higher accuracy. The second limitation is the design of study, which can confine to determine the exact effects of variables on life satisfaction. At the same time, the presence of physical and psychological co-morbidities in the elderly can limit the appropriate assessment of satisfaction with life. However, further investigations are needed to identify the exact causes and risk factors of life satisfaction in the elderly people.

\section{CONCLUSIONS}

We concluded that ethnic Malay and living with a partner were the significant contributing factors to impact 
positively life satisfaction in subjects. Furthermore, age, education, debt, employment, cognition, sleep hours, taking salary, sex differences, and home ownership status were not significant predictors of life satisfaction. However, further studies are required to identify potential factors that improve life satisfaction in the elderly.

\section{ACKNOWLEDGMENTS}

The authors gratefully acknowledge the co-operation of all volunteers who participated in this research. The authors wish to acknowledge the financial support from the Ministry of Education for this study. In addition, the authors also thank all staff for their efforts in data collection.

\section{REFERENCE LIST}

Anand, M., \& Arora, D. (2009). Burnout, life satisfaction and quality of life among executives of multi national companies. Journal of the Indian Academy of applied Psychology. 35: 159-164.

Borg, C., Hallberg, I. R., \& Blomqvist, K. (2006). Life satisfaction among older people (65+) with reduced self-care capacity: the relationship to social, health and financial aspects. Journal of clinical nursing. 15: 607-618.

DeLamater, J., \& Moorman, S. M. (2007). Sexual behavior in later life. Journal of Aging and Health. 19: 921 945.

Diener, E. (1994). Assessing subjective well-being: Progress and opportunities. Social indicators research. 31: 103-157.

Diener, E. (2009). Subjective wellbeing. In E. Diener (Ed.), The science of well-being. The collected works of Ed Diener. Social Indicators Research Series, 37.

Diener, E., Gohm, C. L., Suh, E., \& Oishi, S. (2000). Similarity of the relations between marital status and subjective well-being across cultures. Journal of cross-cultural psychology. 31: 419-436.

Eshkoor, S. A., Hamid, T. A., Nudin, S. S. a. H., \& Mun, C. Y. (2014). The Effects of Social Support, Substance Abuse and Health Care Supports on Life Satisfaction in Dementia. Social Indicators Research. 116: 535-544.

García, R. F.-B., Zamarrón, M. D., Bravo, M. D. L., Martínez, M. Á. M., del Moral, R. S., López, P. M., \& Nicolás, J. D. (2011). Successful ageing: criteria and predictors. Psychology in Spain. 94-101.

Hervé, C., Bailly, N., Joulain, M., \& Alaphilippe, D. (2012). Comparative Study of the Quality of Adaptation and Satisfaction with Life of Retirees According to Retiring Age. Psychology. 3: 322.

Hombrados-Mendieta, I., García-Martín, M. A., \& Gómez-Jacinto, L. (2013). The relationship between social support, loneliness, and subjective well-being in a Spanish sample from a multidimensional perspective. Social indicators research. 114: 1013-1034.

Jan, M., \& Masood, T. (2007). 5 Factors Affecting Life Satisfaction among Women. Journal of psychological researches. 51: 63.

Jean-Louis, G., Magai, C., Cohen, C., Zizi, F., von Gizycki, H., DiPalma, J., \& Casimir, G. (2001). Ethnic differences in self-reported sleep problems in older adults. Sleep-New York-. 24: 926-936.

Kaliterna, L. L., Prizmic, L. Z., \& Zganec, N. (2004). Quality of life, life satisfaction and happiness in shift-and non-shiftworkers. Revista de Saúde Pública. 38: 3-10.

Kaufman, A. V., Kosberg, J. I., Leeper, J. D., \& Tang, M. (2010). Social support, caregiver burden, and life satisfaction in a sample of rural African American and White caregivers of older persons with dementia. Journal of Gerontological Social Work. 53: 251-269.

Melek, Ö. (2004) A study on the life satisfaction of elderly individuals living in family environment and nursing homes. Turkish Journal Of Geriatrics. 7: 33-36.

Netuveli, G., \& Blane, D. (2008). Quality of life in older ages. British medical bulletin. 85: 113-126.

Onishi, C., Yuasa, K., Sei, M., A. Ewis, A., Nakano, T., Munakata, H., \& Nakahori, Y. (2010). Determinants of life satisfaction among Japanese elderly women attending health care and welfare service facilities. The Journal of Medical Investigation. 57: 69-80.

Silva, P. A. d. (2014). Individual and social determinants of self-rated health and well-being in the elderly population of Portugal. Cadernos de saude publica. 30: 2387-2400. 
Troxel, W. M., Robles, T. F., Hall, M., \& Buysse, D. J. (2007). Marital quality and the marital bed: Examining the covariation between relationship quality and sleep. Sleep medicine reviews. 11: 389-404.

Zimmerman, S., Sloane, P. D., Williams, C. S., Reed, P. S., Preisser, J. S., Eckert, J. K., Boustani, M., \& Dobbs, D. (2005). Dementia care and quality of life in assisted living and nursing homes. The Gerontologist. 45: 133-146. 